\title{
A ESTETIZAÇÃO POLÍTICA DOS LUGARES DE MEMÓRIA
}

\author{
DANIELE BORGES BEZERRA \\ Universidade Federal de Pelotas (UFPel) \\ JULIANE CONCEIÇÃO PRIMON SERRES \\ Universidade Federal de Pelotas (UFPel)
}

\section{RESUMO}

Neste artigo discute-se a preservação da memória em antigos leprosários, instituições criadas, nas décadas de 1930 e 1940 para isolar pessoas acometidas pelo Mal de Hansen. Com a política de profilaxia da lepra, o exercício do poder disciplinar, perpassado pela perseguição e pelo isolamento social, gerou um tipo de experiência traumática compartilhada. O sofrimento humano, de pessoas que tiveram seus direitos violados por políticas de estado, tem sido foco de atenção no campo do Patrimônio Cultural, pois as memórias incômodas, de eventos que marcaram a humanidade, dos quais Auschwitz se tornou um emblema, não podem cair no esquecimento. Chama-se atenção, contudo, para a tendência à estetização dos usos políticos da memória. É necessário observar as formas narrativas pelas quais as memórias são contadas, em lugares que se configuram como lugares de memória.

PALAVRAS-CHAVE:

Instituições Totais; Patrimônio; Narrativa; Acervos; Experiências

\section{ABSTRACT}

In this article the preservation of memory in ancient leper colonies, institutions created in the 1930s and 1940 s to isolate people affected by Hansen's disease, is discussed. With leprosy prophylaxis policy, the exercise of disciplinary Power, perpassed by persecution and by social isolation, generated a kind of shared traumatic experience. Human suffering, of people Who have had their rights violated by state policies, has been the focus of attention in the Cultural Patrimony Field, because uncomfortable memories of events that have marked humanity, of which Auschwitz became na emblem, can not become forgotten. Attention is drawn, however, to the trend to aestheticization of the political uses of memory. It is necessary to observe the narratives through which memories are told, in places which are configurated as places of memory.

KEYWORDS: Leprosaria; Total Institutions; Heritage; Narrative; Collections; Traumatic Experience.

Traumáticas. 


\section{Práticas de poder e políticas de ativação da memória}

A biopolítica ${ }^{1}$ exerce um controle sobre a vida em todas as suas dimensões, de modo que as "categorias de transação" - como Estado, Sociedade Civil, Economia, Cultura, Comunidade - são invenções criadas "no próprio jogo das relações de poder" ${ }^{\prime 3}$ para organização de formas de governamentalidade. 0 surgimento do Direito traz consigo o ambivalente fardo de deveres chancelados pelo nascimento de leis e regulamentos que, se de um lado preveem proteção em diversos níveis, de outro não garantem a exequibilidade da mesma e, ainda, promovem meios de coerção sobre a liberdade de indivíduos sociais. Nos meandros do espaço constituído pela prática do Direito (exercício de direitos e deveres), as instituições e discursos são práticas de poder. As sociedades disciplinares ${ }^{4}$, surgidas com a institucionalização de práticas cotidianas de controle e coerção, tais como a escola, o exército e a fábrica, exercem o que o autor considera uma ortopedia política, ou anatomo-política, que visa o controle social a partir da configuração de corpos dóceis. Outro autor, Erving Goffmann ${ }^{5}$ desenvolveu uma teoria sobre estes locais extremamente disciplinados e os definiu como instituições totais "um local de residência e trabalho onde um grande número de indivíduos em situação semelhante, separados da sociedade mais ampla por considerável período de tempo, levam uma vida fechada e formalmente administrada". Mesmo nesses locais, afirmava o autor, as pessoas desenvolvem "uma vida própria que se torna significativa, razoável e normal, desde que você se aproxime dela"6. Há casos mais ou menos expressivos desses tipo de institucionalização, desde prisões e hospitais até casos extremos como poderiam ser os campos de extermínio nazistas.

A dimensão do sofrimento humano evocado pela Shoah faz de Auschwitz um símbolo da barbárie onde o exercício do poder se caracteriza como um abuso contra a alteridade e um atentado à humanidade, infligido ao povo judeu. O Holocausto e os lugares de extermínio na Europa, podem ser interpretados, à luz do século XXI, como uma ferida aberta que coloca em evidência a dupla natureza da memória em sua estreita complementaridade com o esquecimento. Em tempos de "mnemotropismo"7, é importante refletir

\footnotetext{
${ }^{1}$ FOUCAULT, Michel. Nascimento da biopolítica. Tradução: Eduardo Brandão. São Paulo: Martins fontes, 2008.

${ }^{2}$ FOUCAULT, 2008, p. 404.

${ }^{3}$ Ibid.

${ }^{4}$ FOUCAULT, Michel. Vigiar e punir. Tradução: Raquel Ramalhete. Petrópolis: Editora Vozes, 2004.

${ }^{5}$ GOFFMAN, Erving. Manicômios, Prisões e Conventos. São Paulo: Ed. Perspectiva, 7a ed., 2003, p. 11.

${ }^{6}$ GOFFMAN, 2003, p. 8.

7 CANDAU, Joel. Bases antropológicas e expressões mundanas da busca patrimonial: memória, tradição e identidade. Revista memória em rede. V. 1, n.1, Pelotas, 2009- 2010, p. 44. Para Jöel Candau o mnemotropismo seria um sintoma contemporâneo expresso por uma compulsão memorial. Para o autor esse olhar excessivo sobre o passado e a espetacularização da memória no campo patrimonial podem estar relacionados a um fenômeno que Micehl Wieviorka chamou de "a emergência da vítima". WIEVIORKA apud CANDAU, 2009, p. 44.
} 
sobre "por que" e "como" se preserva a memória relacionada ao sofrimento humano. Para Wieviorka" a memória das perdas, relacionadas a tragédias humanas é uma "memória da afirmação", a lembrança serve como alicerce para o reconhecimento do sofrimento compartilhado e fortalece o grupo. Com a crescente reivindicação do direito à memória abre-se um novo campo de ação patrimonial dedicado à compreensão das memórias difíceis, pois os efeitos destas novas formas de comemoração do passado, ainda não estão claras e, tampouco existe um consenso no que diz respeito aos métodos experimentados pelos meios de transmissão destas novas memórias. Assim, é importante buscar respostas para questões que surgiram nesse século pós-traumatismo, antes que os vestígios sejam naturalizados. Por que lembrar? Como lembrar? De que modo expor o sofrimento, sem estetizar e uniformizar as narrativas? Pois o "como" irá refletir na interpretação dos fatos históricos determinando "de que" e "de quem" são as memórias.

Para Candau, Auschwitz é um "lugar de memória que se impõe a toda Alemanha atual" ${ }^{\prime 9}$, com "una carga traumática que pesa sobre la identidad nacional ${ }^{10}$, e isso ocorre porque o lugar de memória bloqueia o esquecimento. Se relativizarmos o olhar sobre a cena histórica, percebemos que, para além de fronteiras ideológicas ou políticas, estes eventos traumáticos conservam a potência de nos lembrar sobre a capacidade humana em atuar sobre o direito do outro, em nome de um bem maior.

Menos impactante na história, por ser uma medida justificada pela propagação da doença, e por não se tratar de uma indústria de produção de cadáveres, como Auschwitz, mas sem deixar de comportar uma carga memorial, a criação de leprosários no Brasil durante os anos de 1930 e 1940 não deixam de remeter, em alguns aspectos, a esses locais disciplinares e sua patrimonialização no presente representam um desafio. Nesse cenário contemporâneo, de super valorização dos eventos do passado, onde o direito à memória é acionado por um desejo de reconhecimento, percebe-se uma tendência à estetização dos usos políticos da memória. É necessário dedicar atenção às formas narrativas pelas quais as memórias são contadas, em lugares que se configuram como lugares de memória, para que se obtenha coerência narrativa e ética nesse processo.

\section{Hospitais-colônia: microcidades inventadas}

A hanseníase, antigamente denominada lepra, causada pelo microbacterium leprae, também conhecido como "bacilo de Hansen", foi uma

\footnotetext{
${ }^{8}$ WIEVIORKA, Michel. Mémoire, identité et histoire. Pour, n. 181, 2004.

${ }^{9}$ CANDAU, Jöel. Memória e identidade. Traduzido por: Maria Leticia M. Ferreira. São Paulo: Contexto, 2011, p. 157.

10 HUYSSEN, Andreas. Em busca Del futuro perdido: cultura y memória em tiempos de globalización. Tradución de Silvia Fehermann.Buenos Aires: Grafinor, 2001, p. 155.
} 
doença de dispersão mundial que declinou e praticamente desapareceu a partir do século XVI na Europa, tornando-se pouco comum na maioria dos países desenvolvidos. Segundo o informe da Biblioteca de Manguinhos ${ }^{11}$, a hanseníase atualmente é encontrada, sobretudo, no Sudeste Asiático, Índia, África tropical e algumas áreas das Américas (México, Antilhas, Guianas, Venezuela, Colômbia, Bolívia, Brasil e Argentina).

Existem relatos que afirmam que a lepra chegou ao Brasil com os primeiros europeus em 1500 e, a seguir, com os escravos trazidos da África. No século XVIII as pessoas infectadas começaram a sofrer uma forte perseguição, sendo a elas associados o estigma ${ }^{12}$ religioso da contaminação e do pecado. Ocorreu, com isso, uma pressão social e política para retirar os "lazarentos" das ruas. O primeiro local de isolamento para pessoas com lepra no Brasil foi criado em 1640, em Salvador, Bahia, com o lendário Campo dos Lázaros, fundado pela caridade $^{13}$.

Apesar dos esforços para conter a disseminação da lepra no Rio de Janeiro, a doença continuava se espalhando e, no séc. XVII, as autoridades planejaram a criação de um isolamento inspirado no hospital de Salvador, mas a tentativa fracassou devido à carência de recursos. No século XVIII, devido ao crescente número de casos noticiados em todo o país, foram promovidas ações isoladas, praticadas pela caridade, para conter a doença. Medidas como a criação de lazaretos, ou locais para isolar os doentes, seguiram-se ao longo do século XIX como forma de conter a propagação da doença. Foi no século XX que a lepra tornou-se um problema de saúde pública, exigindo ações dos poderes públicos em seu combate:

Na década de 20 havia um clima de pânico social em relação aos doentes. Marginalizados, os portadores da hanseníase não podiam trabalhar e, sem condições de subsistir, mendigavam pelas ruas. No primeiro governo de Getúlio Vargas (1930-45), o combate à "lepra" foi ainda mais disciplinado e sistematizado. Reforçou-se, então, a política de isolamento compulsório que mantinha os doentes asilados em hospitais-colônia ${ }^{14}$.

O "poder médico, enquanto produtor de verdade, num espaço preparado

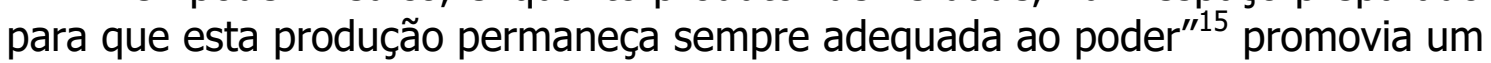
regime de invisibilidade comparável ao empreendido pelos regimes totalitários, onde a "construção social de um sujeito considerado supérfluo e desnecessário,

${ }^{11}$ FIOCRUZ. Biblioteca de Manguinhos. Série doenças: Hanseníase. Acessado em 21/10/2014. Online. Disponível em: <http://www.cpqrr.fiocruz.br/informacao_em_saude/CICT/Hanseniase.htm>2014.

12 O termo "estigma" foi desenvolvimento por Erving Goffman (1993) como um atributo negativo surgido em sociedade a partir da categorização de seus integrantes.

${ }^{13}$ Ibid.

${ }^{14}$ MORHAN. Revista do movimento de reintegração das pessoas atingidas pela hanseníase. Julho/ Agosto de 2007, p.8. Acessado em janeiro de 2015. Online. Disponível em <http://www.morhan.org.br/views/upload/jornal_45.pdf.>

${ }^{15}$ FOUCAULT, Michel. Microfísica do poder. Traduzido por: Roberto Machado. Rio de Janeiro: edições Graal, 1989, p. 125. 
desprovido de sua pessoa jurídica"16 e, por conseguinte, de seus direitos, permitia que esse sujeito fosse retirado do seu meio social.

Os hospitais-colônia são produto de políticas de segregação fomentadas em nível mundial no final do século XIX e início do século $X X$, através das chamadas Conferências Internacionais de Lepra. No Brasil, o combate à lepra esteve a cargo da caridade e filantropia até a organização das políticas públicas de combate à doença do início dos anos de 1920 e, sobretudo, a partir dos anos de 1930 com a instauração do Estado Novo, período no qual a lepra passou a ser considerada sinal de atraso e falta de civilização ${ }^{17}$.

Os projetos dos leprosários no Brasil foram elaborados em 1935 a pedido do Ministério da Saúde, inspirados no modelo norueguês de isolamento, foram executados em lugares afastados dos centros urbanos, de difícil acesso, organizados no molde de microcidades que dispunham de uma estrutura que replicava, em menor escala, a organização necessária para uma vida coletiva, como as instituições totais descritas por Ervin Goffman na obra Manicômios, prisões e conventos ${ }^{18}$. Os hospitais-colônia possuíam um pórtico que delimitava a fronteira entre o mundo dos sãos e o espaço construído com igrejas, pavilhão de esportes, teatro, prisão, cemitério e, inclusive, moeda própria.

Antes do tratamento com as sulfonas ${ }^{19}$, os hospitais-colônia desempenhavam o papel central de dispositivos para a contenção da doença, para impedir a propagação da lepra entre a parcela saudável da população. 0 Decreto Federal $n^{\circ} .968$ de $1962^{20}$ determinou o fim do isolamento compulsório, mas a maioria das pessoas permaneceu nas suas casas, dentro dos antigos lugares de isolamento, sem conseguir projetar novos começos fora desses lugares. Os hospitais-colônia podem ser considerados lugares de memória, uma vez que se configuram como lugares "onde a memória trabalha" ${ }^{21}$ na evocação de emoções negativas que marcaram mais de uma geração.

Não apenas a sentença de reclusão, mas a brutalidade da separação dos filhos saudáveis de seus pais doentes no momento do nascimento, muitos dos quais só foram encontrados depois de adultos, são aspectos dolorosos da memória de quem viveu direta ou indiretamente nesse lugar. Por isso, além de um lugar de memória, o hospitais-colônia podem ser entendidos e identificados

\footnotetext{
${ }^{16}$ ARENDT, Hannah. Origens do totalitarismo. Tradução: Roberto Raposo. São Paulo: Schwarcz, 1998, p. 498.

${ }^{17}$ SERRES, Juliane Conceição Primon. Nós não caminhamos sós: O Hospital Colônia Itapuã e 0 combate à lepra no Rio Grande do Sul (1920-1950) Dissertação (Mestrado em História). Universidade do Vale do Rio dos Sinos (UNISINOS), São Leopoldo, 2004.

${ }^{18}$ GOFFMAN, Erving. Manicômios, Prisões e Conventos. São Paulo: Ed. Perspectiva, 7 a ed., 2003.

${ }^{19}$ Primeira medicação efetiva no tratamento da hanseníase, descoberta em 1944.

${ }^{20}$ FIOCRUZ DECRETO No 968, de 7 de maio de 1962. Acessado em 24 de jul. de 2015. Online. Disponível em: <http://www.fiocruz.br/historiadahanseniase/media/Decreto968.pdf >1962.

${ }^{21}$ NORA, Pierre 1993 apud CANDAU, Jöel. Memória e identidade. Traduzido por: Maria Leticia M. Ferreira. São Paulo: Contexto, 2011, p. 153.
} 
como lugares de sofrimento, o que traz à tona uma noção de "patrimônio incômodo"22.

Quase duas décadas depois, a inclusão de Auschwitz na lista do patrimônio mundial pela UNESCO em 1979 chama a atenção para a importância do reconhecimento de lugares marcados por experiências traumáticas. Assim, a problemática da patrimonialização em lugares marcados pelo sofrimento diz respeito às memórias de milhares de pessoas e de seus descendentes, mas também às ausências e ao indizível, localizados nos lugares "como se os lugares pudessem ser sujeitos e portadores de lembranças, e talvez, possuam uma memória que transcende os homens" ${ }^{\prime 23}$.

Pode parecer imoderado, mas é comum associar os relatos de quem viveu as políticas de isolamento no Brasil com as narrativas dos sobreviventes dos campos de concentração nazistas, pois, embora não houvesse por parte do governo brasileiro e das políticas de saúde pública o objetivo de eliminar a vida, aconteceram muitas mortes subjetivas, infringindo direitos humanos básicos, no mesmo contexto totalitarista ${ }^{24}$ em que a guerra ocorria na Europa. Certamente não podemos desconsiderar a capacidade que as pessoas possuem de burlar as situações extremas e reinventar espaços de alteridade, mesmo em isolamento. Contudo, esta capacidade humana de se reinventar nem sempre é acionada. Muitas vezes os prejuízos são irreparáveis. Não pretende-se com isso criminalizar as políticas sanitárias da época, entretanto é necessário que estes fatos tornem-se conhecidos. É importante frisar que existem diferenças no que tange aos lugares criados para isolar e tratar os pacientes acometidos pela hanseníase, e as pessoas encaminhadas para os campos de concentração e extermínio. Nas colônias a vida continuava, havia um incentivo por parte dos profissionais de saúde para que novos laços afetivos se formassem e as pessoas não viviam na iminência de serem eliminadas. A similaridade entre os dois sistemas talvez esteja associada à perseguição, seguida do isolamento compulsório, e ao preconceito sofrido pelos doentes do mal de Hansen, que também ocorria com o povo judeu, assim como a invisibilidade social garantida por lugares de concentração estrategicamente isolados.

Nesse sentido, os aspectos de violência trazidos à luz pelo Holocausto foram um "evento fundador" na modernidade, "una cifra del siglo XX"25, cuja dimensão deixa de ser apenas local e passa a servir como referência a outros eventos traumáticos, em nível global, uma "herida que se infringió a la civilización occidentaP ${ }^{26}$, como o genocídio em Ruanda (1994), suscitado por rivalidades étnicas que tiveram sua origem ainda no século XIX com a colonização alemã.

\footnotetext{
22 PRATS, Llorenç. Concepto y gestión del patrimonio local. Cuadernos de Antropología Social No 21. UBA, 2005. Acessado em Acessado em 21/10/2014. Online. Disponível em: <http://www.scielo.org.ar/pdf/cas/n21/n21a02.pdf>. 2005.

23 ASSMANN, Aleida. Ricordare: Forme e mutamenti dela memoria culturale. Bologna: ed. Mulino, 2002, p. 331.

${ }^{24}$ ARENDT, Hannah. Origens do totalitarismo. Tradução: Roberto Raposo. São Paulo: Schwarcz, 1998.

25 HUYSSEN, Andreas. Em busca Del futuro perdido: cultura y memória em tiempos de globalización. Tradución de Silvia Fehermann. Buenos Aires: Grafinor, 2001, p. 17.

${ }^{26}$ Ibid., p. 146.
} 
O Holocausto é, nesse sentido, um evento fundador de uma forma de humanidade nunca vista antes, quando a intolerância projeta a ação humana no campo da desumanização e as práticas de poder se manifestam de forma traumática sobre as diferenças. Assim:

En el movimiento transnacional de los discursos de la memória, el Holocausto pierde su calidad de índice del acontecimiento histórico específico y comienza a funcionar como uma metáfora de otras historas traumáticas y de su memória ${ }^{27}$.

Além disso, Huyssen ${ }^{28}$ se refere ao Holocausto como constituinte de uma "estética negativa de la alta modernidad", em grande medida provocada pela forma ficcional dada à narrativa dos fatos que incidiram sobre a memória de quem não viveu o período. Pierre Nora chama a atenção para o processo de acomodação dos restos e para as formas de representação do passado, que caracterizaram-se pela configuração de uma "memória intensamente retiniana e poderosamente televisual" ${ }^{\prime 29}$, portanto, perigosamente associada à narrativa da verdade. O documentário "Shoah", de Claude Lanzmann (1985) ${ }^{30}$, é uma exceção nesse sentido. $O$ filme começa com o retorno de um sobrevivente que, a partir de um trabalho de memória, aciona os eventos ocorridos no lugar sem sensacionalismo. Nesse documentário, a noção de "lugar de memória" no sentido "material, simbólico e funcional" 31 proposto por Pierre Nora, é clara. A queda do Muro de Berlim em 1989, que simbolizou a queda dos regimes totalitaristas, é um ícone da história da humanidade que alimenta a corrente dos Direitos Humanos. Hoje, mais de 70 anos após a criação do campo de Auschiwtz na Europa e dos hospitais-colônia no Brasil, observa-se, no país e no mundo, um movimento organizado a partir de uma díade do reconhecimento, com vistas tanto à preservação da memória quanto à reparação dos danos sofridos por pessoas sujeitadas à violência física e, ou, simbólica, dos quais o sistema disciplinar, e os lugares de isolamento (hospitais- colônia; hospitais psiquiátricos...) ainda evocam fantasmas.

O Movimento de Reintegração das Pessoas Atingidas pela Hanseníase (Morhan) acredita que seja possível pensar a patrimonialização dos hospitaiscolônia a partir de uma política mais ou menos uniforme, com relação à preservação da memória em nível nacional, respeitadas as especificidades e os interesses locais. Percebe-se até o momento, uma movimentação centralizada em torno da reivindicação de direitos, das pessoas que sofreram com as

\footnotetext{
27 HUYSSEN, Andreas. Em busca Del futuro perdido: cultura y memória em tiempos de globalización. Tradución de Silvia Fehermann. Buenos Aires: Grafinor, 2001, p. 17.

28 Ibid., p. 126.

${ }^{29}$ NORA, Pierre. Entre memória e história: a problemática dos lugares. Tradução Yara Aun Koury. In Projeto história. Revista do Programa de estudos de Pós Graduados em história e do Departamento de história da PUC- SP. São Paulo: Educ, 1993, p. 20.

30 LANZMANN, Claude. Shoah. França, 1985. Acessado em 10 de jun. de 2015. Online. Disponível em:<https://www.youtube.com/watch?v=j4lwwAda6x8 >.

${ }^{31}$ Ibid., p. 21.
} 
políticas de isolamento compulsório, que tem como um dos produtos a consolidação de um discurso sobre uma memória compartilhada ${ }^{32}$.

Com representantes em todas as capitais brasileiras, um bom trânsito institucional em organismos como The Nippon Foudation, no Japão, e a Secretaria de Direitos Humanos, no Brasil, o Morhan desempenha um importante papel com a reivindicação e conquista de direitos junto ao poder público, com a ativação performática das memórias de quem viveu nesses lugares e com o estímulo à produção de uma forma de solidariedade social por parte da sociedade civil.

O ex-funcionário do Hospital-Colônia Aimorés, Jaime Prado, aos 15 anos de idade entrou "clandestinamente pelo meio do mato" e foi "conhecer este lugar: a cidade dos excluídos da sociedade". Ele participou da fundação do Morhan nacional, hoje continua atuando no movimento como voluntário e se identifica como narrador da história do recentemente tombado ${ }^{33}$ HospitalColônia Aimorés, já que, para ele "a modernidade tenta apagar com a borracha do esquecimento essa história triste" ${ }^{\prime 34}$.

A reparação que chega pelas indenizações do governo brasileiro parece cumprir com um "dever de memória"35 muito mais simbólico do que concreto, pois a vida das pessoas no isolamento em hospitais-colônia, sejam eles psiquiátricos ou leprosários, é uma experiência em verdadeiros campos de extermínio lento. A começar pela subjetividade dos internos.

Para Artur Custódio, a ressignificação da memória representa uma reparação simbólica do traumatismo do passado que permite projetar ações para o fortalecimento da autoestima e da cidadania no presente:

Então, essa questão da reparação financeira é, na verdade, um pedido de desculpas. [...] para alguns a publicidade dada à situação já resolveria, porque dinheiro nenhum paga o que o pessoal passou. Então, não é uma questão financeira. A questão financeira, ela é simbólica ${ }^{36}$.

Para Tiago Flores, diretor do Morhan nacional, morador da Colônia Santa Izabel em Minas Gerais, filho adotivo de ex-hansenianos e um dos idealizadores do museu em construção no local, as indenizações são positivas quando reduzem os prejuízos históricos e são capazes de

devolver a sua dignidade e fazer com que essas pessoas tenham acesso a alguns bens de consumo que, devido aos prejuízos sofridos pela política de isolamento, não puderam ter

${ }^{32}$ Cf. HALBWACHS. Maurice. A memória coletiva. Traduzido por: Beatriz Sidou. São Paulo: Centauro, 2006.

${ }^{33}$ O Hospital-Colônia Aimorés foi tombado em 2014 pelo órgão de preservação do estado de São Paulo (Condephat).

${ }^{34}$ PRADO, Jaime. Entrevista. Hospital-colônia Aimorés. São Paulo, por e-mail, 2015.

${ }^{35}$ RICOUER, Paul. A memória, a história, o esquecimento. Campinas: Editora Unicamp, 2010, p. 54.

${ }^{36}$ CUSTÓDIO, Artur Entrevista. MORHAN Nacional. Rio de Janeiro, por e-mail, 2015. 
acesso devido a baixa escolaridade e não ingresso no mercado de trabalho ${ }^{37}$.

Artur Custódio, coordenador do Morhan nacional, no Rio de Janeiro, refere-se à justificativa histórica utilizada por profissionais da área médica para o isolamento compulsório, na qual fica claro o quanto o diálogo entre Direitos Humanos e Saúde Pública.

é um diálogo muito frágil. A indenização 11.520 nem sempre é bem interpretada pela área médica, pelos profissionais da saúde, pois a política de segregação era uma política de saúde pública, então não era crime ${ }^{38}$.

Em paralelo à restituição legal, o outro eixo para o reconhecimento patrimonial dos hospitais-colônia no Brasil é a criação de memoriais e museus da memória que preservam elementos do cotidiano institucional no interior dos hospitais-colônia. Os acervos mesclam elementos da cultura material, tanto da área médica (instrumentos de cura, livros médicos, frascos de remédio) e de caráter coletivo (moldes para fabricação de sapatos, carteiras escolares...), quanto instrumentos da vida privada (utensílios de higiene pessoal, álbuns de fotografia e documentos pessoais) que apresentam vestígios da vida em ambiente compartilhado.

Como hipótese, propõe-se que seja possível falar em uma "estetização das políticas de memória" ${ }^{\prime 39}$ como produto das ações de reconhecimento dos eventos traumáticos do passado, a partir de interpretações no tempo presente. Entretanto, considera-se que as diversas emoções ativadas pelos dispositivos de memória talvez não promovam uma comoção em torno das memórias dolorosas, mas valorizem um olhar sobre o cotidiano pitoresco no interior destas instituições. Assim, situamo-nos no espaço subjetivo entre a percepção do visitante e a emoção do antigo morador para problematizar a categoria da vítima e os dispositivos políticos para o reconhecimento de locais de memória marcados por eventos traumáticos.

Os sentidos do passado desprendem-se da materialidade evocativa do lugar e complementam-se com os objetos, documentos e fotografias expostos nos memoriais criados em seus espaços. Mas quais os significados atribuídos a esses lugares e "de que maneiras contam a história" ${ }^{40}$ dos eventos passados?

\footnotetext{
${ }^{37}$ FLORES, Thiago. Entrevista. Hospital-colônia Santa Izabel. Minas Gerais.por e-mail, 2015.

${ }^{38}$ CUSTÓDIO, op. cit..

${ }^{39}$ SELIGMANN- SILVA. Márcio. Estética e política, memória e esquecimento: novos desafios na era do Mal de Arquivo. Unicamp: Remate de Males- 29 (2) jul./dez. 2009. Acessado em 20 de jun. $\quad 2015.2$ Online. Disponível em: <http://revistas.iel.unicamp.br/index.php/remate/article/view/873>

40 WAHNICH, Sophie. Transmettre /'effroi, penser la terreur: Les musées d'une Europe déchirée. Gradhiva [en ligne], 5/ 2007, p.2. Mis en ligne le 12 juillet 2010, Acessado em 01/07/2015. Disponível em: <http://gradhiva.revues.org/692>.
} 
Com relação aos memoriais, resta a pergunta: como narrar o indizível? Ou, ainda, como diria Huyssen ${ }^{41}$ "cómo resolver la transmisión inexorablemente mediática de um trauma de la humanidade a las generaciones nascidas después de las víctimas", já que a multiplicidade de discursos que tornam pública a memória mobilizam valores diferentes de acordo com as suas representações?

Imagem 1: Moldes ortopédicos utilizados na produção de sapatos para pacientes do $\mathrm{HCI}$.

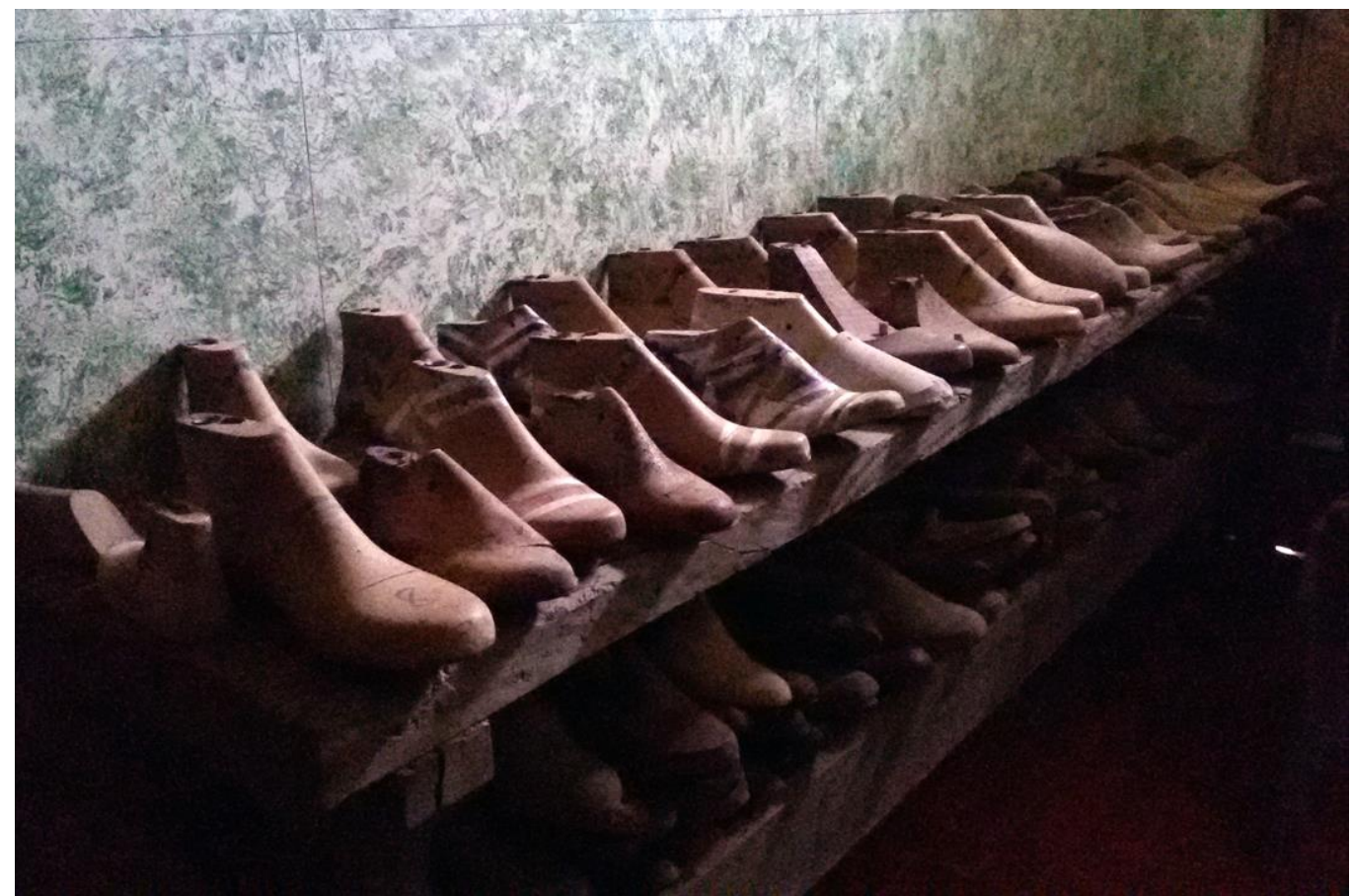

Fonte: Fotografia de Daniele Borges, junho de 2015.

Para Lehrer ${ }^{42}$, ao contrário do que foi dito por Pierre Nora ${ }^{43}$, para quem só existe "lugar de memória" quando não existem mais os meios de memória, os "lugares patrimoniais não são apenas lugares (onde a memória se cristaliza), mas meios da memória, onde abstraídos das histórias nacionais homogeneizantes são postos em causa dentro da narrativa diária e de vida às quais sobrepõem-se histórias individuais'"${ }^{\prime 4}$. Ao considerar a perspectiva dos autores, é possível propor que, num contexto global permeado pela midiatização, a estetização memorial dos lugares seja uma forma de ativação

41 HUYSSEN, Andreas. Em busca Del futuro perdido: cultura y memória em tiempos de globalización. Tradución de Silvia Fehermann.Buenos Aires: Grafinor, 2001, p. 123.

42 LEHRER apud SIMON, Roger; ASHLEY, Susan. Heritage and practices of Public Formation. International Journal of Heritage Studies, n. 16, 4-5, 2010, p. 251.

${ }^{43}$ NORA, Pierre. Entre memória e história: a problemática dos lugares. Tradução Yara Aun Koury. In Projeto história. Revista do Programa de estudos de Pós Graduados em história e do Departamento de história da PUC- SP. São Paulo: Educ, 1993, p. 7.

44 '"Heritage spaces are not just lieux, but milieux de memoire, where abstracted, homogenising national stories are called into question through the daily telling and living of our unique and overlapping individual stories"'. (LEHRER apud SIMON; Ashley, op. cit., p. 251). 
de discursos memoriais influenciada pela mesma cultura retiniana acusada por Pierre Nora ${ }^{45}$.

Assim, ao pensar os prejuízos históricos provocados pelo exercício do poder, a ativação política da memória com um sentido reparatório que vai ao encontro da ideia de um dever de memória ${ }^{46}$, deve ser considerada sem ingenuidade, para que o processo não resulte na estetização essencialista do referente. Também é fundamental que os profissionais da memória, sobretudo os que atuam no campo das narrativas memoriais, promovam formas plurais para exposição dos vestígios do passado, nas quais os silêncios também sejam condutores potenciais de significado.

No Hospital-Colônia Itapuã, localizado em Viamão no Rio Grande do Sul, foi criado recentemente um Memorial, que ainda está em fase de organização e recebe visitas de grupos restritos, sob agendamento prévio. Localizado na antiga casa das freiras, apresenta aos visitantes um acervo composto por objetos da época, tais como: fotografias, objetos ordinários, equipamentos cirúrgicos, de laboratório, documentos moedas locais, moldes para calçados, etc. Chama a atenção o cenário com um manequim que simula uma pessoa com hanseníase, segundo o estereótipo bíblico dos lazaretos. A pessoa coberta por tecidos, apoiada em uma muleta, com a face encoberta. Ao fundo, uma imagem de Jesus Cristo.

Imagem 2: Detalhe do acervo do Memorial do HCI.

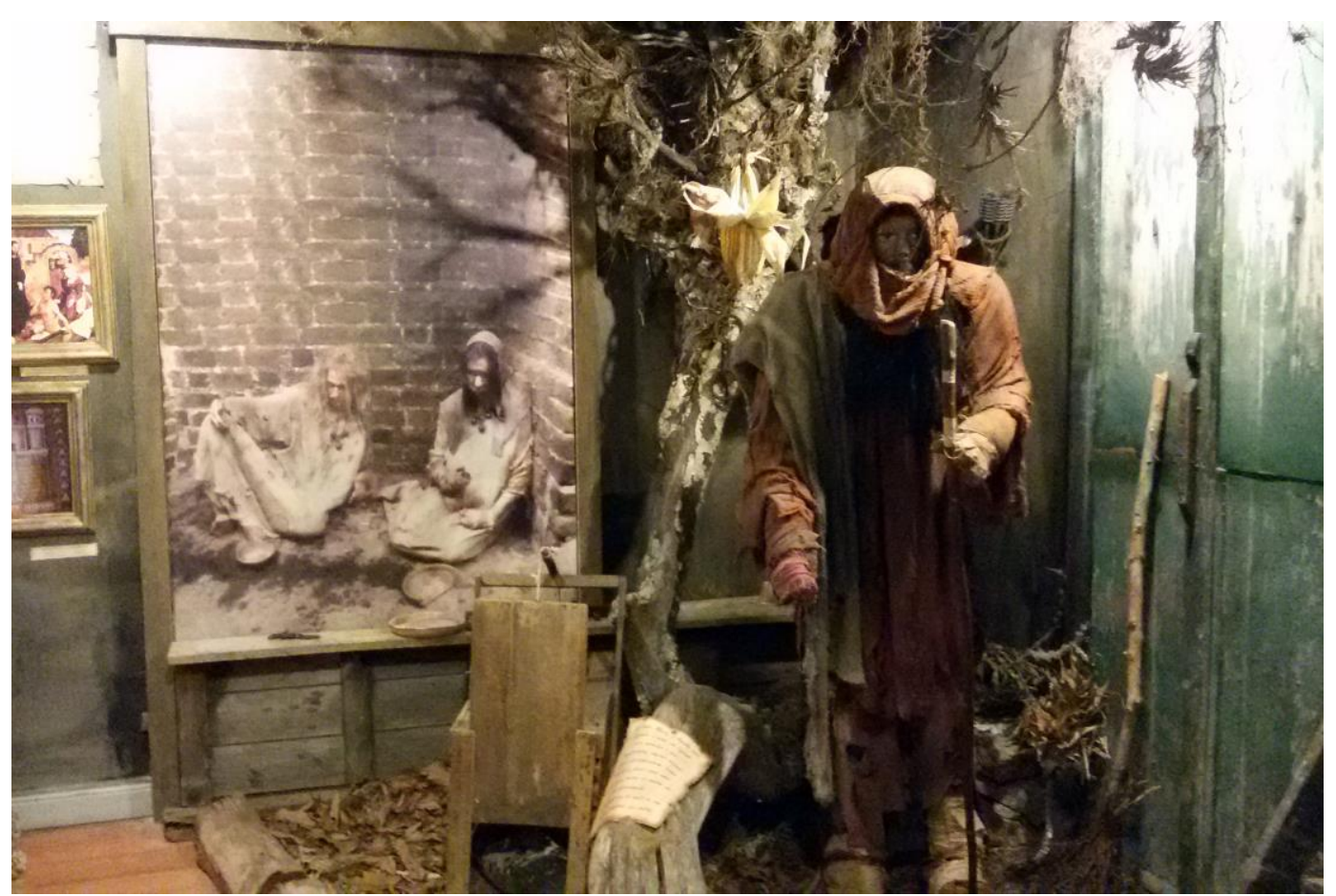

Fonte: Fotografia de Daniele Borges, junho de 2015.

\footnotetext{
${ }^{45}$ Ibid.

${ }^{46}$ RICOUER, Paul. A memória, a história, o esquecimento. Campinas: Editora Unicamp, 2010.
} 
Ao abordar o uso memorial feito pelos objetos em museologia, Octave Debary introduz um texto sobre museologia e patrimonialização dos restes falando da teatralização nos museus: "Les musées exposent des objets qui sont excuse à la théâtralisation" ${ }^{\prime 47}$. O objeto museológico e patrimonial é manipulado como um vestígio, ou resto do passado, conservado e reciclado pelas interpretações do presente. Ao considerarmos os objetos como potenciais vestígios do passado, carregados de marcas que permitem contar uma história, é preciso estar atento a essa "escritura" dos objetos hoje.

Enquanto ícone da memória da hanseníase no Brasil, os hospitaiscolônia, continuam sendo um capítulo da história da saúde no Brasil pouco acessível aos leigos sobre o assunto. Enquanto lugares de memória, os antigos leprosários apresentam a dupla e ambígua característica de conservarem, ao mesmo tempo, traços de visibilidade e invisibilidade, tal como proposto por Deleuze em referência à "busca do tempo perdido" 48 : "a Memória implica 'a estranha contradição entre a sobrevivência e o nada'"'49.

Assim, cabe a nós, atores sociais de hoje (pressupõe-se: pesquisadores, comunidade, profissionais da saúde, ex-moradores e atuais, gestores, etc.), escavarmos em busca de vestígios e identificar, entre aquilo que resta e pode ser recuperado das histórias vividas nessas microcidades, elementos da memória aos quais seja importante atribuir o título de Patrimônio.

Não se pode esquecer, assim como afirma Prats ${ }^{50}$, que: "La memoria es cambiante, selectiva, diversa, incluso contradictoria y relativa en todo caso a las situaciones, intereses e interrelaciones del presente [...]". E a ativação do patrimônio, a sua "puesta em valor" tem a ver com os discursos a seu respeito.

Falar em patrimônio no século XXI significa tocar em uma dimensão polissêmica ${ }^{51}$ do reconhecimento que diz respeito à escritura de memórias plurais a partir de narrativas reais ou imaginadas, legitimadas pelo direito de memória. O patrimônio cultural pode ser entendido como categoria de pensamento ${ }^{52}$, logo, como ação social. Assim, pensamento, ação e institucionalização devem ser situados num contexto histórico de práticas de poder com a ativação de versões diversas da identidade representadas pelo patrimônio. Percebe-se, com isso, que a eleição consciente de valores para a

47 DEBARY, Octave. La fin du Creusot ou L'art d'accommoder les restes. Paris: Éditions du CTHS,2002, Collection Le regard de l'ethnologue 13, p.1. Acessado em Acessado em 10/03/2015. Online. Disponível em <www.microsillons.org/collection/CreusotDebary.pdf>. Os museus exibem objetos que são desculpa para a dramatização (Livre tradução).

${ }^{48}$ O caminho de Swann, volume I da obra 'Em busca do tempo perdido' de Proust.

${ }^{49}$ Deleuze, Gilles. Proust e os signos. Tradução: Antonio Carlos Piquet e Roberto Machado. Rio de Janeiro: Forense Universitária, 2010, p. 19.

${ }^{50}$ PRATS, Llorenç. Concepto y gestión del patrimonio local. Cuadernos de Antropología Social No 21. UBA, 2005, p. 16. Acessado em 21/10/2014. Disponível em: <http://www.scielo.org.ar/pdf/cas/n21/n21a02.pdf>.

${ }^{51}$ PRATS, Llorenç. El concepto de patrimônio cultural. Universidad de Barcelona: Política e sociedade. 27, Madrid, 1998, p.63.

${ }^{52}$ GONÇALVES, José Reginaldo. Patrimônio como categoria do pensamento. 2002. Disponível em:

http://gestaocompartilhada.pbh.gov.br/sites/gestaocompartilhada.pbh.gov.br/files/biblioteca/ar quivos/patrimonio_como_categoria_de_pensamento.pdf. Acessado em 10 de jul. de 2015. 
representação dos repertórios patrimoniais é uma prática condutora de discursos tem sido elaborada "por indivíduos concretos, al servicio, más o menos consciente, de ideas, valores e interesses concretos ${ }^{\prime 53}$.

Candau descreve o mecanismo de seleção memorial em sua imbricada relação com a afetividade e a identidade. É possível pensar no patrimônio como uma lente, sem menosprezar o fato de que aquilo que é selecionado pelo enquadramento óptico também pode ser distorcido por ele.

É um 'sistema tensional essencialmente dinâmico que implica as intenções, os valores [...] logo, as motivações, uma afetividade'. Por isso compromete toda a pessoa em sua percepção do mundo. Através da memória o indivíduo capta e compreende continuamente o mundo $[\ldots]^{\prime \prime 54}$.

Enquanto profissionais do patrimônio, atuando em campos multidisciplinares, chama-se a atenção para a necessidade de ruptura com 0 romantismo nacionalista que impregnou e ainda se faz presente nas bases das ações patrimoniais fundadoras, práticas vinculadas à configuração de um conjunto "ideal" representativo da identidade nacional.

A seleção do que é nomeado como relevante para ser preservado deve ser entendida e questionada dentro das relações de poder que constituem o que deve ou não ser considerado patrimônio. Ou, como dito por SeligmannSilva55, claramente influenciado pelo "mal de arquivo" de Derrida56, "todo arquivo implica seleção e, portanto, esquecimento mesmo que parcial de certos aspectos desse passado", e, continua o autor, "o que tem o poder sobre ele deve ser pensado como aquele que tem também as chaves da porta da justiça", uma estrutura jurídica, que fecha também as portas da memória. Assim, antes de naturalizar a categoria "patrimônio", é necessário, tomando emprestado de Derrida" "desconstruir" modelos preconcebidos para que a categoria patrimônio não seja utilizada como bandeira de reconhecimento a partir da qual todos se identificam, capaz de representar as diversas identidades envolvidas nos processos e de restituir as fissuras do passado a partir de um modelo aplicável a tudo.

53 PRATS, Llorenç. El concepto de patrimônio cultural. Universidad de Barcelona: Política e sociedade. 27, Madrid, 1998, p. 68.

${ }^{54}$ CANDAU, Jöel. Memória e identidade. Traduzido por: Maria Leticia M. Ferreira. São Paulo: Contexto, 2011, p. 61.

${ }^{55}$ SELIGMANN- SILVA. Márcio. Estética e política, memória e esquecimento: novos desafios na era do Mal de Arquivo. Unicamp: Remate de Males- 29 (2) jul./dez. 2009, p. 279. Acessado em 20 de jun. de 2015.2 Disponível em: <http://revistas.iel.unicamp.br/index.php/remate/article/view/873>.

${ }^{56}$ DERRIDA, Jacques. Mal de arquivo: uma impressão freudiana. Rio de Janeiro: Relume Dumará, 2001.

${ }^{57}$ DERRIDA, Jacques. Gramatologia. São Paulo: Perspectiva, 1973. 
Afinal de contas, a qual patrimônio nos referimos? Para Simon e Ashley ${ }^{58}$, perguntas como: "patrimônio de quem?, quem está definindo, e para quem?" devem ser consideradas, pois "são questões extremamente importantes que nos auxiliam a evitar 0 nacionalismo redutível que suprime 0 reconhecimento da complexidade multicultural dos estados nação contemporâneos dentro da nossa era da hiperglobalização" ${ }^{\prime 59}$. Perceber os processos de patrimonialização a partir de uma perspectiva multiescalar, pensada do local ao global, é fundamental para compreender que 0 enquadramento dos bens no rol do patrimônio cultural depende muito mais do exercício de políticas sociais, cujo poder é situacional no presente, do que da apropriação de um passado cristalizado como herança universal a priori.

Segundo Pedro Funari (em aula oferecida ao Programa de PósGraduação em Memória Social e Patrimônio Cultural, na Universidade Federal de Pelotas, no dia 14 de abr. de 2015), "não é só o acúmulo de conhecimento que leva ao saber, mas as mudanças paradigmáticas. Nossas percepções estão ligadas às transformações sociais". Ora, sob um ponto de vista institucional, a categoria patrimônio surgiu no século XVIII ${ }^{60}$ e passou por reformulações no período após a Segunda Guerra, quando patrimônio e destruição não eram s, e também em 2001, com a criação da Carta sobre a Diversidade Cultural pela UNESCO, num contexto de intolerância que se ampliou após o atentado às Torres Gêmeas em 11 de setembro de 2011.

É necessário reconhecer a categoria como chave para a ação política de reconhecimento em diversos níveis, haja visto que esta vem sendo utilizada para acionar repertórios patrimoniais e construir patrimônios em diversos contextos históricos da humanidade, de modo a oficializar discursos na busca por uma narrativa de um passado comum, como ocorreu nos séculos XVIII e XIX, e não apenas para (ingenuamente) garantir a preservação da memória e da cultura dos povos em sua diversidade. Pois, como afirma Prats, "Sin poder, podríamos decir em términos generales, no existe el patrimonio"61, e este depende de interesses diversos para que se institucionalize.

Todas as comunidades sempre fizeram uso do passado. Contudo, a patrimonialização não é uma consequência lógica do processo de reconhecimento memorial. Pode-se dizer que essa é uma prática moderna de atribuição de valor. A categoria patrimônio, enquanto referente da memória social e coletiva ${ }^{62}$, constitui-se como um discurso, permeado por diversos interesses e significados.

\footnotetext{
${ }^{58}$ SIMON; ASHLE, op. cit., p. 247-254.

${ }^{59}$ Ibid., p. 247. These are clearly extremely important questions in that they help us resist na all too facile, reductive nationalism which suppresses acknowledgment of the multicultural complexity of contemporary nation states within our era of hyper-globalisation. (Ibid., p.247).

${ }^{60}$ Embora autores como Gonçalves (2002), entendam o patrimônio como categoria de ação e pensamento, presente em diversas culturas em distintos momentos históricos.

${ }^{61}$ PRATS, Llorenç. El concepto de patrimônio cultural. Universidad de Barcelona: Política e sociedade. 27, Madrid, 1998, p. 69.

62 HALBWACHS. Maurice. $A$ memória coletiva. Traduzido por: Beatriz Sidou. São Paulo: Centauro, 2006.
} 
Por fim, ao considerar o patrimônio cultural como "uma invenção e uma construção social" com "caráter polissêmico" ${ }^{63}$, reforça-se a necessidade de acurada atenção para as estéticas narrativas da memória, que ao invés de serem unívocas devem desdobrar-se infinitamente, tantos quantos sejam as memórias, os atores e os contextos narrados.

\section{Sobre as autoras}

Daniele Borges Bezerra é doutoranda em Memória Social e Patrimônio Cultural pela Universidade Federal de Pelotas (UFPel). Mestre em Memória Social e Patrimônio cultural (UFPEL). Atua na linha de pesquisa "Gestão de acervos e instituições de memória". Possui Graduação em Artes Visuais e atua com fotografia em pesquisa. Realizou duas pesquisas em instituições de caráter asilar: Hospital Psiquiátrico São Pedro, em Porto Alegre, onde adquiriu o título de sanitarista e Asylo de Mendigos de Pelotas durante o Mestrado em Memória Social e Patrimônio cultural. Atualmente desenvolve uma pesquisa sobre as narrativas referentes à memória da hanseníase em três hospitais-colônia no Brasil. E-mail: borgesfotografia@gmail.com.

Juliane Conceição Primon Serres possui Licenciatura em História pela Universidade Federal de Santa Maria (2001), mestrado em Museologia na Universidad de Granada (Espanha, 2010), mestrado em História pela Universidade do Vale do Rio dos Sinos (2004) e doutorado em História pela Universidade do Vale do Rio dos Sinos (2009). É professora na Universidade Federal de Pelotas no curso de Museologia e no Programa de Pós-Graduação em Memória Social e Patrimônio Cultural. Tem experiência na área de Museologia e História. E-mail: julianeserres@gmail.com.

Artigo recebido em 24 de agosto de 2015. Aprovado em 10 de outubro de 2015.

63 PRATS, op. cit., p. 63. 